\title{
Prevalence and Factors Associated with Self-Medication in Dermatology in Togo
}

\author{
Koussake Kombaté, ${ }^{1}$ Julienne Noude Técléssou, ${ }^{1}$ Bayaki Saka, ${ }^{1}$ Abla Sefako Akakpo, ${ }^{1}$ \\ Koudjouka Odette Tchangai, ${ }^{1}$ Abas Mouhari-Toure, ${ }^{2}$ Garba Mahamadou, ${ }^{1}$ \\ Waguena Gnassingbé, ${ }^{1}$ Aurel Abilogun-Chokki, ${ }^{1}$ and Palokinam Pitché ${ }^{1}$
}

\author{
${ }^{1}$ Service de Dermatologie et IST, CHU Lomé, Université de Lomé, Lomé, Togo \\ ${ }^{2}$ Service de Dermatologie et IST, CHU de Kara, Université de Kara, Kara, Togo \\ Correspondence should be addressed to Bayaki Saka; barthelemysaka@yahoo.fr
}

Received 28 June 2017; Accepted 19 October 2017; Published 12 November 2017

Academic Editor: Craig G. Burkhart

Copyright (C) 2017 Koussake Kombaté et al. This is an open access article distributed under the Creative Commons Attribution License, which permits unrestricted use, distribution, and reproduction in any medium, provided the original work is properly cited.

\begin{abstract}
Objective. This study aimed to determine the prevalence of and factors associated with self-medication in dermatology in Lomé, Togo. Methods. We conducted an analytical cross-sectional study from February to April 2016 in 2 dermatology departments in Lomé. Univariate and multivariate logistic regression models were carried out to identify possible factors associated with selfmedication. Results. A total of 711 patients were included in the study. The mean age $( \pm \mathrm{SD})$ of the patients was $26.6 \pm 6.9$ years and the sex ratio (male/female) was 0.6. The main dermatologic diseases recorded were immunoallergic dermatoses (39.7\%) and infectious skin diseases (22.6\%). Two-thirds (481/711; 66.7\%) of the patients had practiced self-medication before consultation in dermatology units. In multivariate analysis, factors associated with self-medication were female sex $(\mathrm{aOR}=1.44 ; 95 \% \mathrm{CI}=[1.01$, $2.05])$, duration of dermatologic disease more than one year $(\mathrm{aOR}=1.79 ; \mathrm{IC}=[1.19,2.68])$, adnexal dermatoses $(\mathrm{aOR}=2.31 ; 95 \% \mathrm{IC}$ $=[1.03-5.21])$, keratinization disorders $(\mathrm{aOR}=4.23 ; 95 \% \mathrm{CI}=[1.36-13.13])$, and fungal skin infections $(\mathrm{aOR}=5.43 ; 95 \% \mathrm{CI}=[2.20$, 13.38]). Conclusion. Our study confirms that self-medication practice is very common among patients with dermatologic diseases in Lomé and has identified associated factors.
\end{abstract}

\section{Introduction}

In sub-Saharan Africa, there is a wide range of therapeutic options, ranging from modern medicine to traditional medicine, religious cults or healing prayer, and selfmedication. In this wide range, self-medication occupies an important part for social, economic, and psychological reasons [1]. The World Health Organization (WHO) defines selfmedication as practices by which people deal with aches and health conditions with drugs that are approved and available without prescription and are safe and effective when used according to inscriptions [2]. In addition, self-medication is called anarchic when treating a real or imagined pathological condition by drugs selected without medical advice or without consulting a health care professional in his area of competences [2]. This includes self-prescribing but excludes drug addiction [3]. In dermatology, self-medication can be the cause of serious drug reactions [4-8]. A previous study conducted in dermatology units in Lomé, reported a prevalence of self-medication at $44 \%$ [9], but it had not identified associated factors. The aim of this study was to determine the prevalence of and factors associated with self-medication in patients with dermatologic diseases in Lomé, Togo.

\section{Materials and Methods}

2.1. Study Design. An analytical cross-sectional study was conducted from February to April 2016 in two dermatology units (dermatology unit of CHU Campus and dermatology center of Gbossimé) in Lomé.

2.2. Study Population and Sampling. During the study period, all patients aged over 15 years who consulted for dermatologic diseases for the first time and who gave their consent were 
included in the study. The cost of dermatological consultation in these centers was 3000 CFA (5 euros) for patients without health insurance and 600 CFA (1 euro) for patients with health insurance.

2.3. Data Collection. A semistructured questionnaire was used to collect data through an interview in French or in the local language, conducted by the clinic officers to ensure good understanding of the questions.

The questionnaire included sociodemographic information, health insurance status, clinical features, and history of treatments before the admission in dermatology unit. In this study, we considered medical prescription as any treatment received on medical prescription by a health professional. A self-medication was considered as all other aspects of therapeutic used by patients (self-prescription, traditional medicine, and religious prayers).

2.4. Data Analysis. Data entry and analysis were performed using Epi-info version 3.5.1 software. For continuous variables, mean and standard deviation were calculated while for categorical variables we calculated proportions. Pearson chisquare test was used in bivariate analysis. The significance threshold was set at 5\%. Multivariate backwards stepwise logistic regression analysis was performed to identify associated factors of self-medication. All variables significant during bivariate analysis at a $p$ value less than 0.05 were introduced in a logistic regression model to appreciate the adjusted effect and derive the adjusted odds ratio (aOR) of each on the primary outcome, "self-medication" expressed as a dichotomous variable. A 95\% level of confidence was applied throughout.

\section{Results}

3.1. Characteristics of the Study Population. In total, 711 patients were included in the study during the study period, of which 439 were women. The mean age of the patients was $26.58 \pm 6.9$ years (range: $15-74$ years). Of the 711 patients, $17 \%$ had health insurance, $79.7 \%$ had formal education, and more than two-thirds traveled less than 15 kilometers to consult a dermatologist. The main dermatologic diseases were immunoallergic dermatoses (39.7\%) and infectious skin diseases $(22.6 \%)$ (Table 1 ).

3.2. Medications before Admission in Dermatology. Previous therapies were reported in $529(74.4 \%)$ of the 711 patients prior to admission to dermatology units. Of these 529 patients, 48 (8.9\%) had used medical prescription only and 481 (91.1\%) had used self-medication only or associated with medical prescription. In total, of the 711 participant patients, $481(67.7 \%)$ practiced self-medication only or associated with medical prescription for their dermatologic disease before consultation in dermatology unit. The main examples of medicines used in self-medication were traditional drugs (mixed decoctions of medicinal plants and ingredients), Chinese drugs, or modern medical drugs without medical advice. In bivariate analysis, factors associated with self-medication were female sex $(p=0.02)$, education level $(p=0.02)$, distance traveled to see a dermatologist more 30 kilometers $(p=0.04)$, duration of dermatologic disease more than one year before consultation $(p=0.03)$, and types of skin diseases $(p<0.01)$ (Table 1$)$.

In multivariate analysis, factors associated with selfmedication prior to consultation in dermatology were female $\operatorname{sex}(\mathrm{aOR}=1.44 ; 95 \% \mathrm{CI}=[1.01,2.05])$, duration of dermatologic disease more than one year $(\mathrm{aOR}=1.79 ; 95 \% \mathrm{CI}=$ $[1.19,2.68]$ ), and having developed the following 3 types of skin diseases: adnexal dermatoses $(\mathrm{aOR}=2.31 ; 95 \% \mathrm{IC}=$ [1.03-5.21]), keratinization disorders $(\mathrm{aOR}=4.23$; 95\% $\mathrm{CI}=$ $[1.36-13.13])$, and fungal skin infections $(\mathrm{aOR}=5.43 ; 95 \% \mathrm{CI}$ $=[2.20 ; 13.38])$. High education level was a protective factor against self-medication $(\mathrm{aOR}=0.52 ; 95 \% \mathrm{CI}=[0.30-0.89])$ (Table 2).

\section{Discussion}

This study confirms that self-medication is widely practiced among patients with dermatologic diseases in Lomé. It identified 5 factors associated with self-medication which are female sex, duration of dermatologic disease more than one year before consultation, and having developed the following type of skin diseases: adnexal dermatoses, keratinization disorders, and fungal skin infections. High education level is found as a protective factor against self-medication. Finally, we found that having or not a health insurance does not influence the practice of self-medication.

The prevalence of self-medication we report in this study is higher than those reported previously in the same unit. Indeed, the prevalence of self-medication was $44 \%$ in patients with dermatologic diseases [9] and 47\% among patients who developed Stevens-Johnson and Lyell syndromes [5]. The sincerity of information gathered during the interview with some patients having the fear or the shame of confessing to their practice of self-medication could explain the large differences. Other studies have reported prevalence of selfmedication varying between $6 \%$ and $46.7 \%$ among patients with dermatologic diseases $[10,11]$. The frequency of selfmedication reported in our study $(67.7 \%)$ is almost similar to one $(71.9 \%)$ reported among patients with rheumatic diseases in Burkina Faso [12]. The pressure of the family in decision-making, the difficulties of access to a dermatology specialist and the embarrassment or shame of the disease, and especially the availability of multiple therapies outside health facilities and drugs delivery points are as many factors that encourage self-medication in sub-Saharan Africa. In dermatology, self-medication can lead to many cutaneous reactions; preventive actions and health education in the community are necessary to reduce or treat this problem.

In our study, the female sex, duration of dermatologic disease more than one year before consultation, and 3 types of skin diseases were factors associated with self-medication. The female sex was also identified in the study of Ouédraogo et al. [12] as a factor associated with self-medication in rheumatic diseases. Both studies show that the female sex is a risk factor for self-medication regardless of the specialty concerned. The likely explanation we propose is the women's easy access to illicit medicines in markets and streets often 
TABLE 1: Sociodemographic and clinical characteristics of patients with dermatologic diseases practicing self-medication in Lomé, 2016.

\begin{tabular}{|c|c|c|c|c|}
\hline \multirow{2}{*}{ Characteristics of patients } & \multirow{2}{*}{$\begin{array}{c}\text { Total } \\
N=711(\%)\end{array}$} & \multicolumn{2}{|c|}{$\begin{array}{l}\text { Self-medication } \\
\qquad N=711\end{array}$} & \multirow{2}{*}{$p$ value } \\
\hline & & $\begin{array}{c}\text { Yes } \\
N(\%)\end{array}$ & $\begin{array}{c}\text { No } \\
N(\%)\end{array}$ & \\
\hline \multicolumn{5}{|l|}{ Age } \\
\hline More than 60 years & $9(1.3)$ & $5(55.5)$ & $4(44.5)$ & \multirow{3}{*}{0.40} \\
\hline $35-60$ years & $193(27.1)$ & $140(72.5)$ & $53(27.5)$ & \\
\hline $15-35$ years & $509(71.6)$ & $336(66.0)$ & $173(44.0)$ & \\
\hline \multicolumn{5}{|l|}{ Sex } \\
\hline Female & $439(61.8)$ & $284(64.7)$ & $155(35.3)$ & \multirow{2}{*}{0.02} \\
\hline Male & $272(38.2)$ & $197(72.4)$ & $75(27.6)$ & \\
\hline \multicolumn{5}{|l|}{ Health insurance } \\
\hline No & $590(83.0)$ & $406(68.8)$ & $184(31.2)$ & \multirow{2}{*}{0.13} \\
\hline Yes & $121(17.0)$ & $75(61.9)$ & $46(38.1)$ & \\
\hline \multicolumn{5}{|l|}{ Education level } \\
\hline Nonschooled & $144(20.3)$ & $98(68.1)$ & $46(31.9)$ & \multirow{4}{*}{0.02} \\
\hline Primary school & $180(25.3)$ & $136(75.6)$ & $44(24.6)$ & \\
\hline Secondary school & $241(33.9)$ & $161(66.8)$ & $80(33.2)$ & \\
\hline High level school & $146(20.5)$ & $86(58.9)$ & $60(41.1)$ & \\
\hline \multicolumn{5}{|l|}{ Distance traveled } \\
\hline Less than 15 kilometers & $564(79.3)$ & $369(65.4)$ & $195(34.6)$ & \multirow{4}{*}{0.04} \\
\hline 15-30 kilometers & $59(8.3)$ & $42(71.2)$ & $17(28.8)$ & \\
\hline 30-100 kilometers & $62(8.7)$ & $49(79.0)$ & $13(21.0)$ & \\
\hline More than 100 kilometers & $26(3.7)$ & $21(80.8)$ & $5(19.2)$ & \\
\hline \multicolumn{5}{|c|}{ Duration of dermatologic disease before consultation } \\
\hline Less than 3 months & $233(32.8)$ & $145(62.2)$ & $88(37.8)$ & \multirow{4}{*}{0.03} \\
\hline 3-6 months & $136(19.1)$ & $61(44.9)$ & $75(55.1)$ & \\
\hline 6-12 months & $55(7.7)$ & $9(16.4)$ & $46(83.6)$ & \\
\hline More than 12 months & $287(40.4)$ & $266(92.7)$ & $21(7.3)$ & \\
\hline \multicolumn{5}{|l|}{ Reasons for consultation } \\
\hline Immunoallergic dermatosis & $282(39.7)$ & $194(68.8)$ & $88(31.2)$ & \multirow{12}{*}{$<0.01$} \\
\hline Tumoral dermatosis & $21(3.0)$ & $11(52.4)$ & $10(47.6)$ & \\
\hline STI & $19(2.7)$ & $14(73.7)$ & $5(26.3)$ & \\
\hline Adnexal dermatosis & $55(7.7)$ & $38(69.1)$ & $17(30.9)$ & \\
\hline Bacterial skin infections & $53(7.4)$ & $37(69.8)$ & $16(30.2)$ & \\
\hline Viral skin infections & $28(3.9)$ & $13(46.4)$ & $15(53.6)$ & \\
\hline Fungal skin infections & $70(9.8)$ & $61(87.1)$ & $9(12.9)$ & \\
\hline Parasitic skin infections & $11(1.5)$ & $9(81.8)$ & $2(18.2)$ & \\
\hline Keratinisation disorders & $29(4.1)$ & $24(82.8)$ & $5(17.2)$ & \\
\hline Dyschromia & $41(5.8)$ & $24(58.5)$ & $17(41.5)$ & \\
\hline Dysimmunity dermatosis & $46(6.5)$ & $26(56.5)$ & $20(43.5)$ & \\
\hline Others skin diseases & $56(7.9)$ & $30(53.6)$ & $26(46.4)$ & \\
\hline
\end{tabular}

STI: sexual transmitted infections.

used in self-medication. Unlike the study of Ouédraogo et al. [12], high education level was a protective factor against self-medication in our study. Indeed, educated patients know the misdeeds of self-medication and therefore could avoid it. Similar findings were reported in a Mexican study where the illiterate and the low-educated subjects were those who practiced more self-medication [13].

We also identified the fungal skin infections as being associated with the risk of self-medication. Poudyal and Joshi [14] noted that self-medication for dermatophytosis 
TABLE 2: Factors associated with self-medication among patients with dermatologic diseases in Lomé, 2016.

\begin{tabular}{|c|c|c|}
\hline Characteristics of patients & $\mathrm{aOR}$ & $95 \% \mathrm{CI}$ \\
\hline Female sex & 1.44 & {$[1.01 ; 2.05]$} \\
\hline \multicolumn{3}{|l|}{ Education level } \\
\hline Nonschooled & Ref & \\
\hline Primary school & 1.28 & {$[0.76 ; 2.15]$} \\
\hline Secondary school & 0.89 & {$[0.55 ; 1.43]$} \\
\hline High level school & 0.52 & {$[0.30 ; 0.89]$} \\
\hline \multicolumn{3}{|l|}{ Distance traveled } \\
\hline Less than 15 kilometers & Ref & \\
\hline 15-30 kilometers & 1.27 & {$[0.68 ; 2.35]$} \\
\hline 30-100 kilometers & 1.89 & {$[0.94 ; 3.78]$} \\
\hline More than 100 kilometers & 2.13 & {$[0.76 ; 5.98]$} \\
\hline \multicolumn{3}{|c|}{ Duration of dermatologic disease before consultation } \\
\hline Less than 3 months & Ref & \\
\hline $3-6$ months & 0.99 & {$[0.61 ; 1.59]$} \\
\hline $6-12$ months & 0.90 & {$[0.47 ; 1.72]$} \\
\hline More than 12 months & 1.79 & {$[1.19 ; 2.68]$} \\
\hline \multicolumn{3}{|l|}{ Reasons for consultation } \\
\hline Other skin diseases & Réf & \\
\hline Immunoallergic dermatosis & 1.84 & {$[0.99 ; 3.38]$} \\
\hline Tumoral dermatosis & 0.96 & {$[0.33 ; 2.80]$} \\
\hline STI & 2.78 & {$[0.85 ; 9.06]$} \\
\hline Adnexal dermatosis & 2.31 & {$[1.03 ; 5.21]$} \\
\hline Bacterial skin infections & 1.94 & {$[0.85 ; 4.39]$} \\
\hline Viral skin infections & 0.66 & {$[0.25 ; 1.72]$} \\
\hline Fungal skin infections & 5.43 & {$[2.20 ; 13.38]$} \\
\hline Parasitic skin infections & 3.47 & {$[0.64 ; 18.79]$} \\
\hline Keratinisation disorders & 4.23 & {$[1.36 ; 13.13]$} \\
\hline Dyschromia & 1.26 & {$[0.54 ; 2.92]$} \\
\hline Dysimmunity dermatosis & 0.99 & {$[0.43 ; 2.25]$} \\
\hline
\end{tabular}

STI: sexual transmitted infections.

was frequent and the most commonly used medicines for self-medication were topical steroids alone or associated with antifungal drugs. The chronic, recurrent, and pruritic characteristics of some dermatophytoses probably explain this fact. Finally, having chronic (duration of dermatologic disease more than one year before consultation) or persistent (adnexal dermatoses and keratinization disorders) dermatoses leads the patients to practice self-medication.

\section{Limitations}

The main limitation of this study is related to the sincerity of the information gathered during the interview, with some patients having the fear or the shame of confessing to their practice of self-medication. This could explain the large difference between the rate reported in this study and those reported previously in the same unit. Due to the crosssectional study design of this study, we could not assess the temporality of the associated factors and the outcome.

\section{Conclusion}

Our study confirms that self-medication is widely practiced among patients with skin diseases in dermatology units in Lomé and identified associated factors which are female sex, delay of consultation more than one year, having dermatologic diseases such as fungal skin infections, adnexal dermatosis, or keratinization disorders. It is necessary for decision-makers to develop strategies to bring dermatology services closer to the population especially in remote areas. In addition strengthening health promotion among the population will improve the use of health services and reduce selfmedication.
Abbreviations
aOR: Adjusted odds ratio
STI: Sexual transmitted infections
WHO: World Health Organization. 


\section{Ethical Approval}

This study was approved by the Department of Dermatology of CHU of Lomé, University of Lomé. The authors obtained the approval from the participants.

\section{Consent}

The participants gave their consent, after the verbal explanation was delivered by the clinicians of the participating hospitals. The survey was anonymous and confidential.

\section{Disclosure}

Julienne Noude Técléssou, Abla Sefako Akakpo, Koudjouka Odette Tchangai, Garba Mahamadou, Waguena Gnassingbé, and Aurel Abilogun-Chokki are medical doctors, dermatologists; Koussake Kombaté, Bayaki Saka, Abas Mouhari-Toure, and Palokinam Pitché are medical doctors and professors in dermatology. The Department of Dermatology of CHU of Lomé, Université de Lomé, authorized the publication of this manuscript.

\section{Conflicts of Interest}

The authors declare that they have no conflicts of interest.

\section{Authors' Contributions}

Koussake Kombaté was responsible for the conception of the study, participated in the study design, undertook the field study, conducted the data collection, analysis, and interpretation, and wrote the manuscript. Koudjouka Odette Tchangai was involved in the study design, supervised data collection, and participated in data analysis. Julienne Noude Técléssou, Bayaki Saka, Abla Sefako Akakpo, Abas MouhariToure, Garba Mahamadou, Waguena Gnassingbé, and Aurel Abilogun-Chokki were involved in the data collection, analysis, and interpretation. They have revised and finalized the manuscript. Bayaki Saka and Palokinam Pitché were responsible for the overall scientific management of the study, analysis and interpretation, and preparation of the final manuscript. All the authors read and approved the final manuscript to be submitted for publication.

\section{Acknowledgments}

The authors would like to thank Dr. Landoh, M.D. and M.P.H., for reviewing and copyediting the manuscript and Issifou Yaya, M.P.H. and M.S., for assisting with statistical analysis.

\section{References}

[1] J. K. Manzambi, V. Tellier, F. Bertrand, A. Albert, J. Y. Reginster, and $\mathrm{H}$. Van Balen, "The determinants of recourse behavior at a health center in African urban surroundings: results of a survey in families at Kinshasa, Congo," Tropical Medicine \& International Health, vol. 5, no. 8, pp. 563-570, 2000.
[2] World Heart Organization. Guidelines for the regulatory assessment of medicinal products for use in self-medication. WHO/EDM/QSM/00.1, Geneva 2000.

[3] P. Jolliet, "Self-medication," Revue du Praticien, vol. 54, pp. 1609-1613, 2004.

[4] E. Estève, C. Ah-Toye, A. Nseir, and L. Martin, Use of non prescription drugs for acute dermatoses. A prospective study of 111 hospitalized patients. Ann Dermatol Venereol 2005; 132, 372-3.

[5] B. Saka, K. Kombaté, P. Egbohou et al., "Stevens-Johnson syndrome and toxic epidermal necrolysis in Togo: the role of selfmedication," Annales de Dermatologie et de Venereologie, vol. 139, no. 6-7, pp. 486-487, 2012.

[6] B. B. Adams and P. B. Sheth, "Perianal ulcerations from topical steroid use," Cutis; Cutaneous Medicine for the Practitioner, vol. 69, no. 1, pp. 67-68, 2002.

[7] S. Kastalli, S. El Aidli, R. Daghfous et al., "Fixed drug eruption induced by sulfaguanidine," Annales de Dermatologie et de Venereologie, vol. 131, no. 4, pp. 382-384, 2004.

[8] S. Neema, M. Chatterjee, T. Mukherjee, and S. Jha, "Pigmented contact dermatitis resulting from self-medication for postherpetic neuralgia," Indian Journal of Dermatology, vol. 61, no. 3, pp. 340-341, 2016.

[9] A. Mouhari-Toure, K. Kombaté, B. Saka, S. Akakpo, O. B. T. Boukari, P. Pitché et al., Self-medication for dermatologic conditions in Lomé, Togo. Med Trop 2010; 70: 303-4.

[10] A. Treesirichod, S. Chaithirayanon, and S. Chansakulporn, "Self-medication for dermatologic diseases among children treated at the HRH princess maha chakri sirindhorn medical center," Journal of the Medical Association of Thailand, vol. 98, pp. S135-S139, 2015.

[11] M. Corrêa-Fissmer, A. H. Martins, M. G. Mendonça, and D. Galato, "Prevalence of self-medication for skin diseases: a systematic review," Anais Brasileiros de Dermatologia, vol. 89, no. 4, pp. 625-630, 2014.

[12] D. Ouédraogo, J. W. Zabsonré Tiendrebeogo, E. Zongo et al., "Prevalence and factors associated with self-medication in rheumatology in Sub-Saharan Africa," European Journal of Rheumatology, vol. 2, no. 2, pp. 52-56, 2015.

[13] F. R. Balbuena, A. B. Aranda, and A. Figueras, "Self-medication in older urban Mexicans: an observational, descriptive, crosssectional study," Drugs \& Aging, vol. 26, no. 1, pp. 51-60, 2009.

[14] Y. Poudyal and S. D. Joshi, "Medication practice of patients with dermatophytosis," Journal of Nepal Medical Association, vol. 55, pp. 7-10, 2016. 


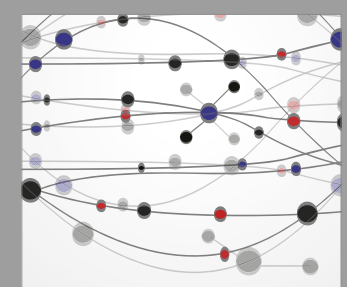

The Scientific World Journal


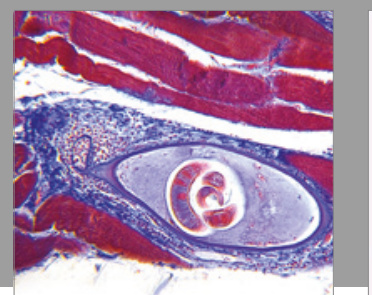

Gastroenterology Research and Practice
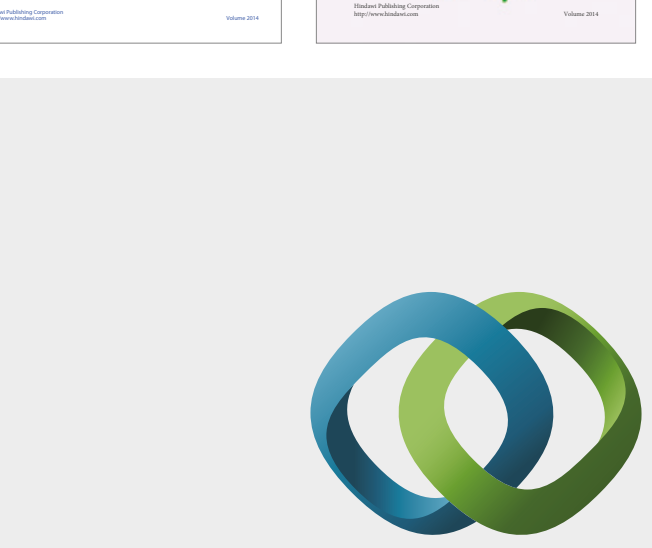

\section{Hindawi}

Submit your manuscripts at

https://www.hindawi.com
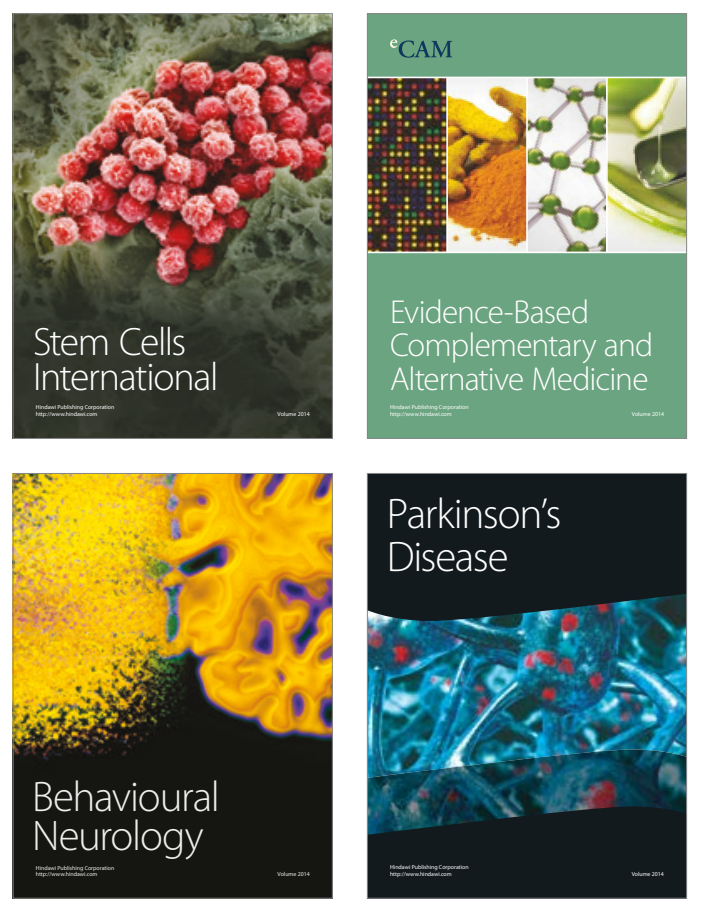
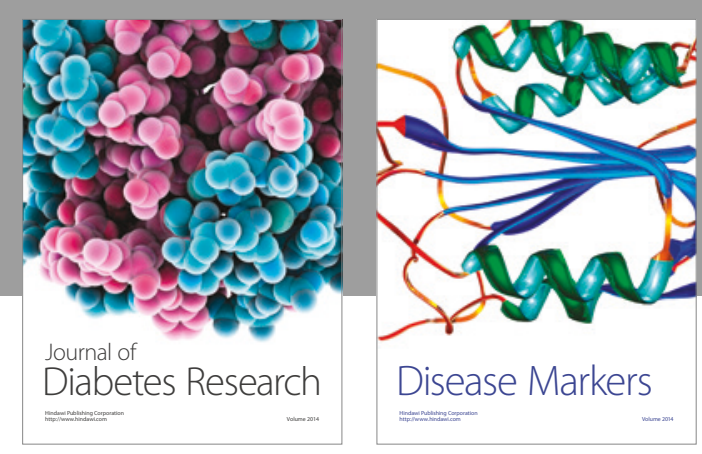

Disease Markers
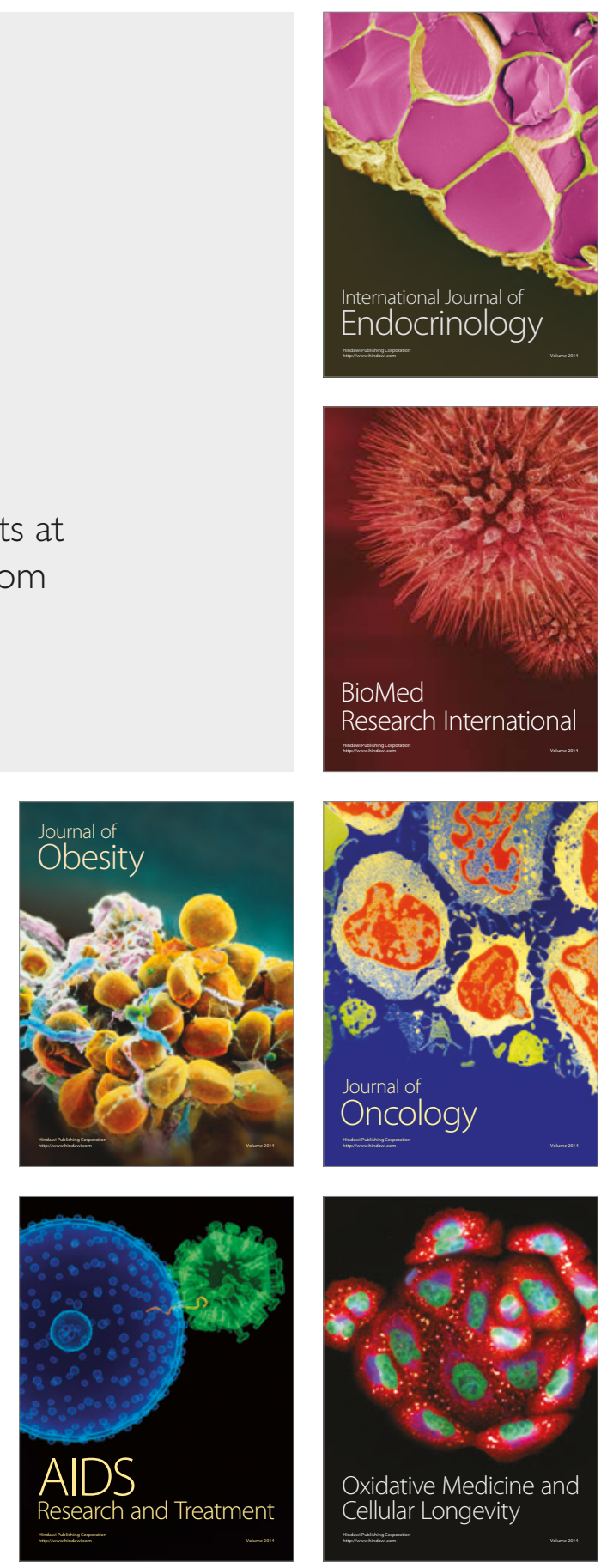